\title{
Pendidikan Rumah Singgah Bagi Anak Kurang Mampu di Kota Batam
}

\author{
Johannes Tarigan, ${ }^{1 *}$ Fredy Simanjuntak ${ }^{2}$, Septerianus Waruwu ${ }^{3}$, David martinus Gulo ${ }^{4}$, \\ Ya'aman Gulo ${ }^{5}$, Josanti ${ }^{6}$, Otieli Harefa ${ }^{7}$ \\ 1, 2, 3, 4, 6, 7 Prodi Teologi, STT Real Batam \\ ${ }^{5}$ Prodi PAK, ST Real Batam \\ *jhnnstarigan@gmail.com
}

\begin{abstract}
Poverty is a condition that is never wanted by anyone. The condition of a large or small city does not guarantee that there will be no poor family in that place. However, the most important of these is what can happen to a poor family. How about their families, especially children born to poor families. Children who cannot afford it will certainly find it difficult to get an education and even their family's economic capacity may not be able to fulfill the three main human needs properly. Therefore, humans as social creatures cannot be separated from other humans. So that there needs to be efforts from other individuals to help each other and the Halfway House becomes a solution for children who come from poor families.
\end{abstract}

Keywords: Education, Halfway House, Children, Family, Poverty

\begin{abstract}
Abstrak
Kemiskinan merupakan keadaan yang tidak pernah diinginkan oleh siapapun. Keadaan kota yang besar atau kecil tidak menjadi jaminan ditempat itu tidak terdapat keluarga yang tidak mampu. Namun, yang paling penting dari hal itu adalah apa yang dapat terjadi terhadap keluarga yang tidak mampu. Bagaimana keluarganya terkhusus anak-anak yang lahir dari keluarga yang tidak mampu. Anak-anak yang tidak mampu tentunya akan kesulitan untuk mendapatkan pendidikan bahkan kemampuan ekonomi kelaurga mereka belum tentu dapat memenuhi tiga kebutuhan pokok utama manusia dengan layak. Oleh karena itu manusia sebagai makhluk sosial tidak dapat lepas dari manusia lainnya. Sehingga perlu ada upaya dari individu lain untuk saling membantu dan Rumah Singgah menjadi salah satu solusi untuk anak-anak yang berasal dari keluarga yang tidak mampu.

Kata kunci: Pendidikan, Rumah Singgah, Anak, keluarga, Kemiskinan
\end{abstract}

\section{PENDAHULUAN}

Kota Batam adalah kota terbesar diprovinsi Kepulauan Riau. Di kota ini kegiatan industri mendominasi ${ }^{1}$ dan termasuk kota yang sering dikunjungi oleh turis dikarenakan lokasi yang berdekatan dengan negara Singapura. Namun, keadaan kota ini tidak meluputkan maysarakat dari gejala sosial.

Dalam portal berita lokal, terdata tempat tinggal masyarakat atau hunian masyarakat tergolong Rumah Liar (Ruli) mencapai 30.868 hingga 50.000 unit. $^{2}$ Rumah liar adalah rumah yang dibangun atas tanah pemerintah yang telah dialokasikan oleh pemerintah untuk kepentingan khusus untuk pengusaha, lahan industri bahkan daerah hutan lindung. Jumlah Ruli yang begitu banyak membuktikan banyaknya masyarakat Kota Batam yang mengalami kesulitan untuk mendapatkan tempat tinggal yang layak dan nyaman bagi mereka. Hal ini menjadi ironi dibalik nama besar dari Kota Batam terdapat juga kenyataan masih banyak masyarakat yang mengalami gejala sosial kemiskinan.

Melihat keadaan ini tentunnya dapat berdampak kepada anak-anak dalam masa pendidikannya. Melihat bahwa tempat tinggal adalah satu dari 3 kebutuhan utama manusia yaitu sandang, pangan, papan. ${ }^{3}$ Tentulah, keadaan tersebut akan berdampak terhadap pendidikan anak.

\footnotetext{
${ }^{1}$ Malindo Andhi Saputra and Rini Rachmawati, "PERKEMBANGAN KAWASAN INDUSTRI DAN PERMUKIMAN DI KOTA BATAM TAHUN 1997-2007 Malindo Andhi Saputra,” Bumi Indonesia 4, no. 1 (2015): 409. 410

${ }^{2}$ Nurul Indra, "Fakta-Fakta Rumah Liar Di Batam Yang Sulit Ditertibkan," Batam News.

${ }^{3}$ Saputra and Rachmawati, "PERKEMBANGAN KAWASAN INDUSTRI DAN PERMUKIMAN DI KOTA BATAM TAHUN 1997-2007 Malindo Andhi Saputra.”410
} 
Meskipun tidak semua dari anak yang bertumbuh di lingkungan Ruli mengalami masalah dalam pendidikan, namun banyak juga dari mereka yang mengalaminya.

Melihat keadaan ini tentunya STT Real terpanggil untuk dapat menjangkau dan memberkati anak-anak dalam lingkungan yang Ruli. Jika kita meliha dari misi Allah dari kitab PL maupun PB Allah inggin semua umat suku bangsa diberkati. Sehingga STT Real bekerja sama sebagai penyedia SDM kepada Yayasan Suluh Bangsa yang bergerak dalam pelayanan Rumah Singgah di Ruli-Ruli Kota Batam. Selain dari memenuhi panggilan Allah STT Real menilai hal tersebut sebagai bentuk upaya yang positif yang dapat menjaga genesari bangsa agar bertumbuh dengan baik.

\section{METODE}

Tulisan ini disusun dengan menggunakan metode kualitatif. Sekolah Tinggi Teologi Real Batam bekerja sama dengan Yayasan Suluh Bangsa menjadi penyedia SDM untuk pelayanan Rumah Singgah. Selain dari pendekatan langsung dilakukan juga pengkajian dalam tulisan-tulisan terkait yang memiliki value mengenai pendidikan anak dan pelayanan Rumah Singgah. Membaca dan memyimpulkan hasil. Kegiatan PkM di Rumah Singgah dilakukan sepanjang Januari sampai dengan Bulan Nopember pada tahun 2019. Kegiatan ini dilakukan secara rutin dan bergantian sebagai aktualisasi dosen dan mahasiswa mengajar anak-anak yang berasal dari keluarga kurang mampu.

\section{HASIL DAN PEMBAHASAN}

Melihat keadaan gejala sosial di Batam penulis melihat bahwa Rusing merupakan program yang baik dan memilki potensi yang besar, terkhususnya kepada gereja atau orang percaya. Dengan program ini siapa saja dapat membantu pemerintah dalam upaya membangun generasi bangsa yang cerdas. Menolong anak-anak yang ada dalam keluarga kurang mampu dalam hal pengetahuan atau wawasan dan bahkan karakter anak.

Dengan program ini gereja juga dapat melakukan peranannya di tengah-tengah masyarakat gereja tersebut berada. Adapun pentingnya pelayanan Rusing dilakukan pertama, karena pelayanan Rusing memiliki keterkaitan dengan panggilan Allah terhadap orang percaya. Kedua, anak yang kurang mampu membutuhkannya. Dan ketiga, menghasilkan hal-hal yang positif.

\section{Keterkaitan Rusing Dengan Misi Allah}

Secara umum Rumah Singgah adalah program pelayanan yang meiliki tahapan-tahapan yang mencakup penjangkauan, indetifikasi anak, resosialisasi, pemberdayaan anak, pemberdayaan orang tua dan terminasi. ${ }^{4}$ Tahapn-tahapan dari program ini menjadikannya program yang bagus untuk dilakukan. Karena program ini tidak dibatasi dengan anak yang menjadi target dari pelayanan namun orang tua dari anak juga bahkan menyentuh seluruh aspek kehidupan dari anak. Jika meliha dalam misi Allah terhadap panggilan-Nya kepada Abraham jelas sekali Allah menghendaki agar setiap umat suku bangsa diberkati. Demikian juga jika kita melihat kesamaan misi Allah dalam PL ataupun PB. Walaupun dalam PL misi Allah seolah-olah terfokus kepada bangsa Israel sebagai umat pilihan Allah, tetapi dalam kedau Kitab tersebut Allah menunjukkan kasih-Nya kepada semua manusia. Dalam Matius 25:31-46 kita dapa melihat dari cerita Yesus kepada murid-murid bahwa Allah menghendaki setiap orang percaya saling membantu dan menolong terhadap kesusahan yang dimiliki orang lain, tanpa melihat atau memandang hubungan, satatus dan golongan yang dimiliki orang yang memerlukan pertolongan. Dalam cerita itu orang percaya dituntuk agar memiliki sikap yang mudah memberi

${ }^{4}$ Fikriryandi Putra, Desy Hasanah, and Eva Nuriyah H, "PEMBERDAYAAN ANAK JALANAN DI RUMAH SINGGAH,” Share Social Work Jurnal 5, no. 1 (2016): 51-64, http://jurnal.unpad.ac.id/share/article/view/13118. 62 
pertolongan, dan jelas dari kisah itu kita dapat mengetahui orang-orang yang tidak meliki kasih dalam dirinya pada akhirnya akan masuk pada penyiksaan yang kekal.

\section{Pendidikan Anak Yang Kurang Mampu Tanpa}

Menurut Pusponegoro sudah banyak penelitian yang dilakukan mengenai ini dan kesimpulannya perkembangan dan kehidupan anak sangat dipengaruhi oleh keadaan keluarga baik itu dari segi ekonomi ataupun bukan. Namun keadaan ekonomi keluarga paling besar mempengaruhi anak usia dini dala menjalani pendidikan. ${ }^{5}$ Hal ini lumrah dan sering terjadi, terkhusunya di Kota Batam dimana kebutuhan ekonomi yang tinggi dan juga biaya pendidikan yang tidak murah. Tidak jarang kita dapat menemukan kesnjangan pendidikan atau penggolongan anak bersekolah. Jika anak yang bersekolah berasal dari keluarga yang memiliki ekonomi yang baik tentu dia akan berada dalam lingkungan sekolah yang ternama, dan tentunya akan sulit dijumpai anak-anak yang berasal dari anak keluarga yang teraf ekonominya menengah berada disana apalagi anak dari keluarga yang tidak mampu. Dan juga dalam keluarga itu kebutuhan yang harus dipenuhi bukan hanya pendidikan anak, ada sandang, pangan dan papan yang harus di penuhi oleh keluarga terhadap anak.

Pusponegoro juga mengatakan dampak kemiskinan dalam keluarga akan menghantam semua anggotanya, dan hal itu menimbulkan dampak hebat pada anak. ${ }^{6}$ Dengan demikian, anak-anak yang berasal dari keluarga yang tidak mampu terancam tidak mendapatkan pendidikan. Meski pendidikan tidak termasuk dalam tiga kebutuhan pokok utama manusia, namun diluar dari ketiga hal itu yang ada hal penting lainnya yang dibutuhkan oleh anak dan keluarga seperti kesehatan, pertumbuhan karakter dan mentalitas.

Dari hasil pengamatan penulis melihat pelayanan Rumah Singgah yang dilakukan oleh Yayasan Suluh Bangsa di Kota Batam. Ada banyak anak-anak yang membutuhkan Rumah Singgah. Penulis menyimpulkan demikian dikarenakan Yayasan ini sudah memiliki kurang lebih 16 titik Rumah Singgah. Seluruh tempat pengadaan Rumah Singgah berada di Ruli-Ruli.

Singgih dalam Rahmad M mengatakan bahwa anak adalah generasi atau penerus yang menentukan keberlangungan hidup dari keluarga hingga negara. ${ }^{7}$ Tentunya setiap orang tua memiliki keinginan supaya anak-anaknya dapat bertumbuh dengan baik, baik secara jasmani maupun rohani. Tidak sedikit orangtua yang dapat kita jumpai melakukan berbagai upaya yang keras demi anak mendapatkan pendidikan yang baik. Walau pada akhirnya dikarenakan keterbatasan kemampuan yang dimiliki oleh setiap orangtua, tentu ada yang berhasil memperjuangkan anaknya dan ada juga yang pada akhirnya kebutuhan pendidikan anak tidak terpenuhi. Tetapi pastinya setiap orangtua ingin anaknya mendapatkan pendidikan.

\footnotetext{
${ }^{5}$ Novi Hidayat Pusponegoro, "Kemiskinan Anak Usia Kurang Dari Lima Tahun Pada Rumah Tangga Dengan Rata-Rata Pengeluaran Yang Terletak Pada Kuantil Pertama Tahun 2008-2010 DI INDONESIA," SMERU 16, no. 4 (2013): 1-21.1

${ }^{6}$ Ibid. 7

${ }^{7}$ Rahmad M, “Perilaku Sosial Anak Putus Sekolah,” Equilibrium IV, no. 2 (2016): 184-193.186
} 


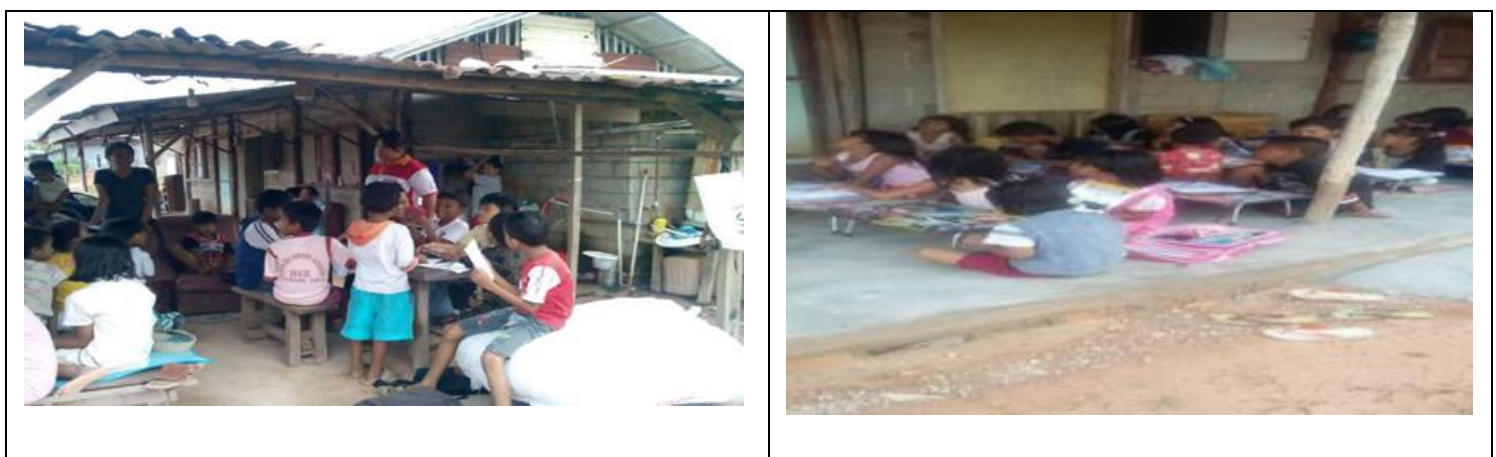

\section{Gambar 1. Tim PkM Mengajar Anak-anak Dari Keluarga Kurang Mampu di Rumah Singgah}

\section{Peranan Rumah Singgah}

Bila kita mencari artikel atau jurnal yang terkait mengenail Rumah Singgah di internet, kita akan mendapatkan semua artikel itu merujuk kepada Rumah Singgah dan anak jalanan. Namu bila kita melihat value dari apa yang Rumah Singgah lakukan terhadap anak-anak jalanan maka kita akan pahami bahwa selain dari anak jalanan, anak-anak yang berasal dari keluarga tidak mampu juga membutuhkan Rumah Singgah.

Menurut Rahmad M, sekolah memiliki empath point penting bagi anak. Pertama, perilaku dan karakteristik. Kedua, proses kognitif. Ketiga, faktor lingkungan. Keempat, latar budaya. ${ }^{8}$ Dari empat point penting ini yang akan membentuk kelakuan, kemampuan dan pembawaan dari anak terhadap lingkungan dan pola akrifitas anak. Terjadinya perkembangan kognitif anak melalui pengasuhan yang baik. Bahkan dengan menerima pendidikan yang baik mencegah timbulnya penyakit-penyakit sosial.

Inannna menjelaskan bahwa pendidikan moral membantua anak yang didik untuk mengenal dan menyadari pentingnya nilai-nilai moral yang seharusnya dijadikan panduan bagi sikap dan perilakunya sebagai manusia, baik secara perorangan maupun bersama-sama dalam suatu masyarakat. Nilai moral mendasari prinsip dan norma hidup baik yang memandu sikap dan perilaku manusia sebagai pedoman dalam hidupnya. Kita semua tentu mengetahui, kualitas hidup seseorang ditentukan oleh nilai-nilai, dan termasuk di dalamnya yaitu nilai moral. ${ }^{9}$ Sementara itu dalam Rahmad M dijelaskan bahwa anak yang putus sekolah tentu tidak mendapat didikan yang demikian sehingga memiliki peluang untuk melakaukan perilaku sosial yang tidak terkendali bahkan dapat mengarah kepada tindak kriminal. ${ }^{10}$

Dalam Daniel Pelayanan Rumah Singgah dijelaskan tidak mengacu kepada standar layanan Dinas Sosial, namun lebih mempertimbangkan keadaan lingkungan disekitar. ${ }^{11}$ Rumah Singgah adalah usaha yang dilakukan dengan baik secara sadar dan terencana agar terjadinya peningkatan terhadap anak. Begitulah yang dilakukan dalam Rumah Singgah terhadap anak yang kurang mampu. Anak-anak diajar membaca dan memperkenalkan hal-hal yang dapat menambah wawasan anak. Rumah Singgah mengasuh dengan kasih dan menjadi figure teladan yang memberikan contoh kepada anak agar memiliki tujuan yang ingin dicapai dalam hidupnya dan membekali anak dengan kreatifitas-kreatifitas. Selain dari pada itu dalam kegiatan terdapat pembinaan-pembinaan rohani yang memiliki tujuan

\footnotetext{
${ }^{8}$ Ibid. 189

${ }^{9}$ Inanna, "Peran Pendidikan Dalam Membangun Karakter Bangsa Yang Bermoral," JEKPEND 1, no. 1
} (2018): 27-33.30

${ }^{10}$ M, "Perilaku Sosial Anak Putus Sekolah."191

${ }^{11}$ Stefanus Daniel, Sulistyarini, and Supriadi, "Pembinaan Anak Jalanan Melalui Rumah Singgah Holidi Kelurahan Tanjung Hilir Kecamatanpontianak Utara,” Jurnal Pendidikan dan Pembelajaran 2, no. 12 (2013): 1-10.4 
supaya iman anak-anak tersebut bertumbuh dan meiliki hubungan yang benar kepada Tuhan. Agar spiritualitas anak baik dalam bersosial kepada oranglain.

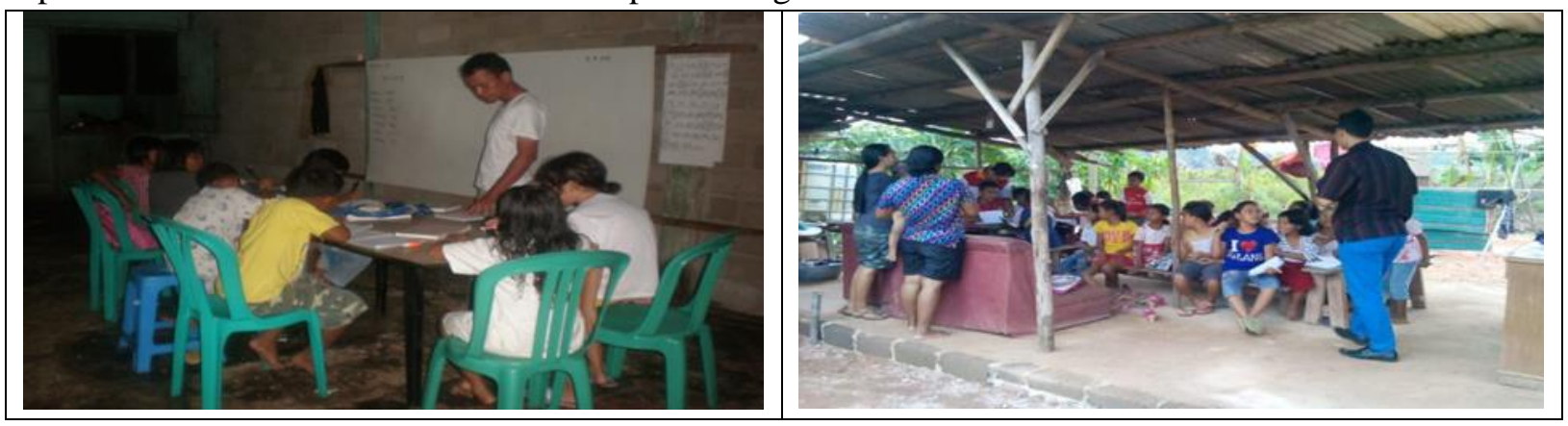

Gambar 2. Suasana Anak-anak Belajar di Rusing Baik Indoor maupun Outdoor

\section{KESIMPULAN}

Ketidak mampuan dalam keluarga memilki dampat negatif kepada seluruh anggota keluarga dan terkhususnya anak. Anak memerlukan pengasuhan dan bimbingan secara ilmu pengetahan maupun, jika hal tersebut tidak dapat terpenuhi kepada anak dalam masa pertumbuhannya akan mempengaruhi karakter dan mental anak dalam menjalani hidupnya. Bahkan dapat berdampak pada gejala sosial atau timbulnya penyakit-penyakit sosial.

Solusi yang terbaik tidak lain daripada memperbaiki ekonomi keluarga. Tentunya hal itu tidak mudah untuk dilakukan, oleh karena itu Rumah Singgah dapat menjadi solusi dan mempermudah beban pemerintah dalam mengayomi generasi-generasi muda yang sedang bertumbuh.

Yang menjadi ugensi dalam pelayanan Rumah Singgah adalah pembinaan iman, karakter, dan budaya anak. Sehingga anak memiliki sikap yang dapat bertanggung jawab.

\section{KEPUSTAKAAN}

Daniel, Stefanus, Sulistyarini, and Supriadi. "Pembinaan Anak Jalanan Melalui Rumah Singgah Holidi Kelurahan Tanjung Hilir Kecamatanpontianak Utara.” Jurnal Pendidikan dan Pembelajaran 2, no. 12 (2013): 1-10.

Inanna. "Peran Pendidikan Dalam Membangun Karakter Bangsa Yang Bermoral.” JEKPEND 1, no. 1 (2018): 27-33.

Indra, Nurul. "Fakta-Fakta Rumah Liar Di Batam Yang Sulit Ditertibkan.” Batam News.

M, Rahmad. "Perilaku Sosial Anak Putus Sekolah.” Equilibrium IV, no. 2 (2016): 184-193.

Pusponegoro, Novi Hidayat. "KEMISKINAN ANAK USIA KURANG DARI LIMA TAHUN PADA

RUMAH TANGGA DENGAN RATA-RATA PENGELUARAN YANG TERLETAK PADA

KUANTIL PERTAMA TAHUN 2008-2010 DI INDONESIA.” SMERU 16, no. 4 (2013): 1-21.

Putra, Fikriryandi, Desy Hasanah, and Eva Nuriyah H. "PEMBERDAYAAN ANAK JALANAN DI

RUMAH SINGGAH.” Share Social Work Jurnal 5, no. 1 (2016): 51-64.

http://jurnal.unpad.ac.id/share/article/view/13118.

Saputra, Malindo Andhi, and Rini Rachmawati. "PERKEMBANGAN KAWASAN INDUSTRI DAN PERMUKIMAN DI KOTA BATAM TAHUN 1997-2007 Malindo Andhi Saputra.” Bumi

Indonesia 4, no. 1 (2015): 409. 